\title{
Evaluation of Qualitative Study Investigating Telepsychiatric Consultation Model
}

\author{
Katbryn Rooney, MD, University of New Mexico, Albuquerque, New Mexico \\ Ann Fam Med 2020;18(5):iii. https://doi.org/10.1370/afm.2593.
}

The Annals of Family Medicine encourages readers to develop a learning community to improve health care and health through enhanced primary care. Participate by conducting a journal club. We encourage diverse participants to think critically about important issues affecting primary care and act on those discussions. ${ }^{1}$

\section{HOW IT WORKS}

In each issue, the Annals selects an article and provides discussion tips and questions. Post a summary of your conversation in our online discussion. (Open the article, click on the eLetters tab, and submit a comment.) Discussion questions and information are online at: https://www.AnnFamMed.org/content/AJC.

\section{CURRENT SELECTION}

\section{Article for Discussion}

Al Achkar M, Bennett IM, Chwastiak L, et al. Telepsychiatric consultation as a training and workforce development strategy for rural primary care. Ann Fam Med. 2020:18(5):438-445.

\section{Discussion Tips}

Primary care plays an essential role in the treatment of behavioral health disorders. In rural settings, there is a large burden of mental health disorders that are often treated by primary care clinicians because of a lack of available specialists. The collaborative care model focuses on behavioral health integration that aims to enhance treatment of behavioral disorders in the primary care setting by adding the support of care management and psychiatric consultation. ${ }^{2}$ The current study by Al Achkar et al presents a qualitative study of telepsychiatric consultation as a method of continuous training and workforce development in the primary care settings with an established collaborative care model in rural areas. ${ }^{3}$

\section{Discussion Questions}

- What question is asked by this study and why does it matter?
- How does this study advance beyond previous research and clinical practice on this topic?

- What are semistructured interviews? Who performed and analyzed the interviews?

- To what degree can the findings be accounted for by: o How participants were selected or excluded?

o The use of one-on-one interviews? The use of semistructured interviews?

o How the findings were analyzed using thematic analysis?

- How comparable is the study sample to similar patients in your practice?

o Does your practice feature a behavioral health integration model? Could it or should it be used in your practice?

o Does your practice utilize telehealth for consultation with specialists? Does your practice utilize telehealth to connect with patients?

-What are the main study findings?

o Do you have similar experiences to the clinicians interviewed in this study?

-What contextual factors are important for interpreting the findings?

- How did the research expand the understanding of "what is going on here"? (ie, compare Figure 1 and Figure 2)

- How might this study change your practice?

- What researchable questions remain?

\section{References}

1. Stange KC, Miller WL, McLellan LA, et al. Annals Journal Club: It's time to get RADICAL. Ann Fam Med. 2006:4(3):196-197. http:// annfammed.org/cgi/content/full/4/3/196.

2. Powers DM, Bowen DJ, Arao RF, et al. Rural clinics implementing collaborative care for low-income patients can achieve comparable or better depression outcomes. [published online ahead of print, July 23, 2020]. Fam Syst Health. doi:10.1037/fsh0000522.

3. Al Achkar M, Bennett IM, Chwastiak L, et al. Telepsychiatric consultation as a training and workforce development strategy for rural primary care. Ann Fam Med. 2020:18(5):438-445. 